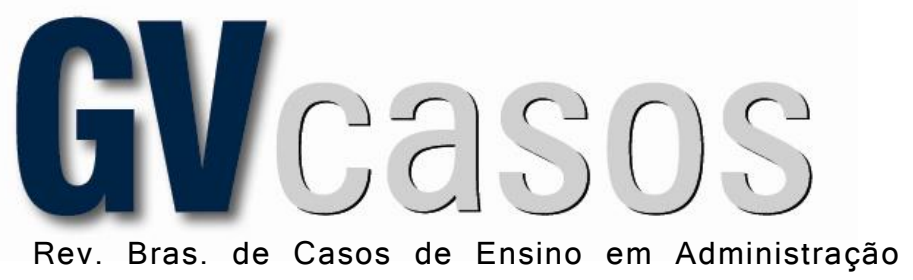

DOI: http://dx.doi.org/10.12660/gvcasosv4n1c1

\title{
LIVRARIA CULTURA: ESTÁ BOM, MAS PODERIA ESTAR MELHOR ${ }^{1}$ Cultura Bookstore: it's good, but it could be better
}

MAURíCio Gerbaudo Morgado - mauricio.morgado@ fgv.br

Escola de Administração de Empresas de São Paulo da Fundação Getulio Vargas - São Paulo, SP, Brasil

Submissão: 26/09/2013 | Aprovação: 08/03/2014

\section{Resumo}

Como a incorporação de novos dados e o uso de sistemas de informação gerenciais podem acrescentar nova luz à resolução de problemas em empresas de varejo?

Este caso pode ser trabalhado em cursos de graduação e pós-graduação em disciplinas em que se discutam temas relacionados ao varejo e marketing em geral. Pode servir também como apoio em cursos de tecnologia da informação. Em marketing e varejo, endereça os seguintes conceitos: segmentação, posicionamento, remuneração, motivação e produtividade da equipe de vendas, além de sistemas de informação gerenciais, mais especificamente mensuração do fluxo de clientes e produtividade de lojas.

Palavras-chave: Sistemas de informação, Resolução de problemas, Varejo, Marketing, Tecnologia.

\begin{abstract}
How can the inclusion of new data and the use of management information systems throw new light on problem-solving in retail companies?

This case can be worked with on graduate and post-graduate courses in disciplines that discuss topics related to retail and marketing, in general. It can also serve as support in IT courses. In the marketing and retail areas it addresses the following concepts: segmentation, positioning, compensation, the motivation and productivity of the sales team and management information systems, more specifically measuring customer flow and store productivity.
\end{abstract}

Keywords: Information Systems; Problem Solving; Retail; Marketing; Technology.

O ano de 2011 foi muito bom para o varejo brasileiro. Em média, o setor experimentou taxas de crescimento real ao redor de $6,5 \%$, comparativamente a 2010 . Claro que, dentro do varejo, nem todos os setores tiveram esse mesmo crescimento. $\mathrm{O}$ varejo de livros, jornais, revistas e papelaria cresceu 5,8\%. Animados estavam os varejistas que comercializavam materiais de escritório, informática e comunicação - esses experimentaram números de crescimento próximos de $19 \%{ }^{2}$.

\footnotetext{
${ }^{1} \mathrm{O}$ presente caso foi desenvolvido com o patrocínio da Virtual Gate. O autor agradece o apoio e a abertura da equipe da Livraria Cultura.

${ }^{2}$ Dados da PMC-Pesquisa Mensal do Comércio. Disponível em: <www.ipeadata.gov.br〉.
} 
No começo de agosto de 2011, apesar dos bons resultados e do clima otimista no País e na empresa, a alta administração da Livraria Cultura suspeitava de que as coisas poderiam estar ainda melhores. Conhecida por sua eficiência, citada como exemplo pela maioria dos consultores de varejo, alguém de fora poderia pensar que tudo estava muito bom e que "em time que está ganhando não se mexe". Mas esse não era o pensamento de Sérgio Herz, presidente da empresa. Numa reunião com Rodrigo de Castro, diretor-geral, os dois chegaram à conclusão de que havia muito mais potencial a ser explorado e de que seria possível obter mais produtividade da já azeitada máquina que era a empresa.

Os dois dirigentes, baseados em resultados das pesquisas do tipo "comprador misterioso", sabiam que, pela cultura de servir, vigente na empresa, as equipes comerciais das lojas tinham a tradição de responder a perguntas, trazer o que o cliente solicitasse e, logo em seguida, deixá-lo à vontade na loja, sem a preocupação de fechar a venda ou, ao menos, encaminhá-lo ao caixa. Sérgio e Rodrigo, no entanto, sabiam que um dos segredos do sucesso da empresa era exatamente a capacidade de fazer o cliente sentir-se em casa. Longe deles implantar métodos de atendimento no estilo "vendedor de sapatos". Mas será que nada poderia ser feito para fechar mais vendas?

\section{Primeiras providências}

Bem ao modo da companhia, os gerentes das 14 lojas foram chamados pela diretoria para discutir o assunto. A proposta do encontro foi apresentar-lhes o problema e pedir sugestões para o aumento de produtividade desejado pela empresa, para gerar mais fechamentos de vendas. Dez dos quatorze gerentes estavam presentes.

Inicialmente, as reações e respostas dos gerentes centraram-se na preocupação que tinham de tornar o atendimento muito agressivo, prejudicando a imagem da empresa. Os diretores afastaram imediatamente esse ponto, garantindo-lhes que, se algo fosse feito nessa direção, seria muito suave, sem nunca comprometer o posicionamento da empresa.

Outra possibilidade discutida no encontro foi a de incrementarem ações de merchandising, cartazeamento e precificação, tornando-as um pouco mais agressivas no ponto de venda. Nesse momento, foi a diretoria que interveio. Os dois diretores, em uníssono, afastaram qualquer ideia nesse sentido. Interferir no visual da loja, até mesmo precificar individualmente cada produto, feriria frontalmente o posicionamento - as lojas perderiam o aspecto acolhedor semelhante ao de uma biblioteca ou, até mesmo, à sala de estar do cliente, e isso estava fora de cogitação.

Depois de uma discussão que durou duas horas, os gerentes e a diretoria optaram por treinar e insistir com a força de vendas para que, ao menos, passasse a acompanhar o cliente até o caixa, buscando o fechamento da venda, ainda que de maneira soft. O combinado foi que, bem ao estilo do varejo, a mensagem seria passada à equipe já na segunda semana de agosto. Os dados de venda da segunda quinzena daquele mês seriam acompanhados, para verificação dos progressos.

\section{Desdobramentos}

$\mathrm{Na}$ metade de setembro, nova reunião com os gerentes foi agendada. As vendas estavam no curso normal, contudo nenhum progresso foi notado relativamente ao que havia sido discutido na reunião do início de agosto. O indicador itens por compra não havia crescido em nenhuma loja, e as vendas por vendedor também estavam inalteradas. Havia fortes indícios de que a equipe não estava respondendo às novas diretrizes.

Questionados pela diretoria, os gerentes da loja atribuíram o problema ao fluxo de clientes. A explicação corrente foi que as vendas não cresciam porque não havia clientes excedentes para a equipe trabalhar. Essa explicação foi fortemente abraçada pelos gerentes das lojas instaladas nos shopping centers. Segundo eles, a culpa era dos shoppings, que não conseguiam atrair mais clientes. Mencionavam, também, que o mercado estava superexplorado, que havia enorme sobreposição entre as áreas de influência desses empreendimentos e que estavam todos disputando o mesmo consumidor. 
Todas as explicações faziam sentido, eram perfeitamente adequadas ao momento, encaixavam-se perfeitamente à realidade do mercado, à voz corrente do setor. Mesmo assim, Sérgio e Rodrigo sentiam que algo mais poderia ser feito. A dúvida era: o quê? Estava na hora de mergulhar no problema e analisar números loja a loja. Os dados coletados na ocasião encontram-se na seção "Parte 1- Analisando os Dados de 2011".

\section{Livraria Cultura}

Em 2011, a Livraria Cultura contava com 14 lojas e empregava mais de 1,5 mil funcionários. Reconhecida como um caso de sucesso nacional, "cada loja é um centro de entretenimento, aonde os clientes vão não somente comprar, mas atualizar-se, debater ideias", diz, no website da empresa, Pedro Herz, presidente do Conselho de Administração da Livraria Cultura e que está à frente da empresa há 40 anos. "Nossos livreiros estão sempre prontos a aconselhar o cliente durante as compras ou a ajudá-lo a encontrar o produto que procura. Essa sempre foi uma característica do nosso negócio", complementa ele.

E o público parece concordar com isso. A livraria é tradicional ponto de encontro de intelectuais e leitores. A Cultura é palco de concertos, shows, noites de jazz, palestras, cafés filosóficos e noites de autógrafos em todas as cidades onde está instalada.

A empresa tem uma linha de produtos muito diversa, contando com mais de cinco milhões de títulos de livros, além de CDs, DVDs, games, revistas e uma linha de produtos exclusivos. Em 2009, começou a comercializar também e-books em seu site. Grande parte desse catálogo é comercializado pela internet. Mesmo assim, uma loja física típica tem, em média, 80 mil títulos.

\section{História de empresa}

A história da Livraria Cultura começou quando Eva Herz, mãe do atual presidente do conselho administrativo da rede, teve a ideia de abrir um serviço de aluguel de livros, na sala de sua própria casa, no bairro dos Jardins, na capital paulista. Eram tempos difíceis. Para fugir da perseguição nazista, a família havia deixado Berlim em 1938 e precisava encontrar formas de aumentar o orçamento.

Em 1950, Eva resolveu incrementar o negócio e, além de alugar livros, passou a vendê-los. Nessa época, seu nome já se firmava entre as mães da cidade, que mandavam os filhos à livreira não só para que alugassem ou comprassem exemplares, mas para que também se aconselhassem sobre leituras.

Em 1969, ela abandonou o serviço de aluguel e passou a tocar apenas a livraria, então instalada num sobrado na Rua Augusta, onde as duas salas da frente serviam de loja, e a parte de trás, de residência para a família.

No mesmo ano, Pedro Herz assumiu a gestão dos negócios e realizou o sonho da mãe de instalar-se em um lugar mais amplo, no Conjunto Nacional. Foi nesse endereço que a empresa sedimentou o perfil que a tornou conhecida: uma grande livraria, com qualidade, variedade e bom atendimento.

Na década de 1970, teve início o processo de ampliação de suas instalações no Conjunto Nacional. Em 1973, foi inaugurada a unidade dedicada à informática, aos negócios, às finanças, ao marketing e às ciências. Dezessete anos depois, em 1990, foi aberta a loja especializada em publicações de ensino de línguas estrangeiras e dicionários.

Em 1995, a Livraria Cultura criou seu site na internet e, seguindo tendências mundiais, passou a ser a primeira livraria brasileira a vender livros on-line. No início de 1997, abriu ao público uma loja de 600 metros quadrados no Conjunto Nacional, voltada às áreas de literatura e humanidades. No fim do mesmo ano, reinaugurou sua primeira unidade, totalmente reformada, onde passou a vender exclusivamente livros de arte.

Em 2000, outro grande projeto da diretoria, agora integrada também por Sergio e Fabio Herz, filhos de Pedro, concretizou-se: a Cultura inaugurou sua primeira filial, um espaço de três mil metros 
quadrados no Shopping Villa-Lobos, também na capital paulista. Em julho de 2006, seria a vez de outro shopping da cidade ganhar uma loja: o Market Place.

Três anos antes, em 2003, a Cultura havia aberto sua primeira filial fora de São Paulo, no Bourbon Shopping Country, em Porto Alegre. Em 2004, foi a vez do Recife e, no ano seguinte, de Brasília.

Em 2007, além de pôr em funcionamento suas novas instalações no Conjunto Nacional, a Cultura investiu na renovação de sua identidade visual. Em 2008, abriu uma unidade em Campinas, a primeira fora de uma capital, e inaugurou, ainda, uma loja com conceito inédito de varejo customizado no Conjunto Nacional, chamada Companhia das Letras por Livraria Cultura. No segundo semestre, abriu também uma loja no Bourbon Shopping São Paulo.

Em junho de 2009, abriu a loja Instituto Moreira Salles por Livraria Cultura, com o mesmo conceito da loja da Companhia das Letras. Em novembro, a loja Record por Livraria Cultura. Em maio de 2010, a Livraria Cultura expandiu os negócios na capital federal, inaugurando mais uma loja - agora no Shopping Iguatemi Brasília -, que recebeu a primeira filial do Teatro Eva Herz. Em junho do mesmo ano, abriu sua primeira filial no Ceará, no centro de compras Varanda Mall, em Fortaleza. Em novembro, estreou na capital baiana, no Salvador Shopping, com a segunda filial do Teatro Eva Herz, tradicional espaço na loja do Conjunto Nacional, em São Paulo, que recebe espetáculos estreantes e consagrados, além de talk shows, pocket shows, palestras, debates e mesas-redondas.

Em 2011, a empresa abriu duas unidades, uma no Rio de Janeiro, no Fashion Mall, em São Conrado, e uma em Curitiba, no Shopping Curitiba. Há outra unidade prevista para o Rio de Janeiro, a ser instalada onde funcionava o antigo Cine Vitória, no centro da cidade.

\section{Complexo do Conjunto Nacional}

As instalações no Conjunto Nacional, em São Paulo, onde a Cultura está desde 1969, ocupam o espaço em que funcionava o tradicional Cine Astor. A loja, inaugurada em maio de 2007, é a maior livraria do País, com 4.300 metros quadrados de área distribuídos por três pisos. Quando essa nova unidade foi aberta, os antigos quatro pontos da Cultura, que ficavam espalhados pelo Conjunto, foram fechados. Aos poucos, porém, foram reabertos.

Em dezembro de 2007, foi reaberta uma loja para abrigar o setor de Artes. Em setembro de 2008, outra foi reaberta para ser ocupada pela Companhia das Letras por Livraria Cultura, local onde são vendidos os cerca de 2,5 mil títulos dessa editora. Em junho de 2009, mais um antigo ponto foi reaberto, com o mesmo conceito do anterior, o Instituto Moreira Salles por Livraria Cultura. E, em novembro desse mesmo ano, a terceira loja com esse conceito foi inaugurada, a Record por Livraria Cultura, esta comercializando somente os títulos dessa editora.

A última novidade no Conjunto Nacional veio em abril de 2012, a Geek Store, espaço voltado para o público geek (uma gíria em inglês que define pessoas obcecadas com tecnologia, eletrônica, jogos eletrônicos ou de tabuleiro), onde são comercializados cerca de 10 mil produtos, divididos em games (jogos e consoles), livros, HQs, RPG, Cinema/TV, revistas, trilhas sonoras de cinema e TV, filmes de animação, ficção científica e séries de TV, papelaria, jogos de carta e bonecos colecionáveis. O conceito dessa loja surgiu da própria equipe de funcionários da Livraria Cultura, cabendo à liderança somente a definição do orçamento e dos parâmetros de retorno sobre o investimento.

\section{Cliente da Livraria Cultura}

Como sempre acontece no varejo, o perfil do cliente da Cultura é influenciado pela geografia, pela área de suas lojas. Em termos demográficos, é possível dizer que se trata de pessoas entre 20 e 50 anos de idade, com alto poder aquisitivo, urbanas e com alto nível educacional, de ambos os sexos. Psicograficamente pertencem à classe A, interessam-se por cultura de maneira geral, incluindo aí leitura, teatro e música. São pessoas exigentes e muito bem informadas. 
A Livraria Cultura propõe-se a ser um provedor de soluções culturais para esse cliente de alto nível educacional e social, fornecendo-lhe literatura, leitura e música. A grande variedade de títulos no seu acervo caracteriza a empresa, para esse cliente, como a provedora definitiva desse tipo de produto. "Se não encontrar na Livraria Cultura, não encontrarei em outro lugar", costumam pensar.

Além da variedade, a empresa é reconhecida por ter lojas muito bonitas e um atendimento diferenciado, uma equipe educada e conhecedora do que vende.

\section{Equipe, atendimento e remuneração}

O modelo de atendimento utilizado pela Livraria Cultura é o autosserviço assistido. Pelo fato de as seções das lojas da rede serem bem definidas e sinalizadas, o cliente tem condições de (e é incentivado a) passear pela loja toda. Caso queira consultar um título com mais calma ou ouvir trechos de um $\mathrm{CD}$, pode fazê-lo à vontade. Há poltronas e sofás espalhados pela loja para facilitar a leitura, agregando conforto e descontração ao ambiente. Em lojas como Cine Astor ou Market Place, há escadarias propositadamente e teatralmente construídas para abrigar os que queiram ler e avaliar os títulos disponíveis.

A equipe de funcionários da loja também tem perfil diferenciado, destacando-se o fato de serem conhecedores das áreas nas quais trabalham, além de terem escolaridade acima da média do setor. Os vendedores que cuidam, por exemplo, de música clássica ou jazz são apreciadores desses estilos e capazes de orientar e sugerir produtos aos clientes. Esse perfil de colaborador garante um atendimento também acima da média, reforçando o posicionamento pretendido pela empresa.

Ainda no que se refere a atendimento, tipicamente, o funcionário da Livraria Cultura é tímido na busca do fechamento da venda, fato já de conhecimento da alta administração, conforme anteriormente mencionado. Parece que há uma certa "vergonha" de vender, de buscar o fechamento, a concretização da compra. A própria história da empresa e o perfil do profissional que emprega ajudam a explicar esse elemento da cultura organizacional.

\section{Lojas}

As 14 principais lojas da rede estão em São Paulo, Campinas, Rio de Janeiro, Porto Alegre, Curitiba, Brasília, Recife, Salvador e Fortaleza. Todas localizam-se em shopping centers, com exceção das lojas da Paulista (Cine Astor e Artes). No prédio do Conjunto Nacional, há também as lojas Companhia das Letras, Geek Store, Instituto Moreira Salles, essas tratadas pela empresa de maneira separada, uma vez que são menores e posicionadas de modo distinto. 
PARTE 1 - ANALISANDO OS DADOS DE 2011

Em setembro de 2011, depois da reunião com os gerentes, foi feito um esforço para coleta de informações de desempenho de vendas. Os dados coletados estão na Tabela 1, que fornece, adicionalmente, dados sobre áreas de vendas e número de funcionários por loja.

\section{Tabela 1}

\section{Vendas e funcionários por loja}

(Observação: os nomes das lojas foram mudados e os dados numéricos, disfarçados. Manteve-se a relação entre eles.)

\begin{tabular}{lrrrrrrr}
\hline $\begin{array}{l}\text { VENDAS 2011 } \\
\text { RANKING }\end{array}$ & $\begin{array}{r}\text { Vendas } \\
\text { em itens }\end{array}$ & $\begin{array}{r}\text { NFs } \\
\text { geradas }\end{array}$ & $\begin{array}{r}\text { Itens por } \\
\text { compra }\end{array}$ & $\begin{array}{r}\text { Metragem } \\
\text { da loja }\end{array}$ & $\begin{array}{r}\text { Área de } \\
\text { vendas }\end{array}$ & $\begin{array}{r}\text { N· vende- } \\
\text { dores }\end{array}$ & $\begin{array}{r}\text { N'opera- } \\
\text { cionais }\end{array}$ \\
\hline Jorge Amado & 161.047 & 70.635 & 2,28 & 2.896 & 2.036 & 45 & 63 \\
Mário de Andrade & 141.782 & 74.917 & 1,89 & 2.715 & 2.033 & 45 & 65 \\
Rubem Fonseca & 11.246 & 5.428 & 2,07 & 2.731 & 1.977 & 42 & 61 \\
Nelson Rodrigues & 21.730 & 9.976 & 2,18 & 929 & 791 & 14 & 29 \\
Monteiro Lobato & 118.335 & 56.487 & 2,09 & 2.052 & 1.644 & 40 & 59 \\
José de Alencar & 160.342 & 77.799 & 2,06 & 3.709 & 2.857 & 43 & 65 \\
Lima Barreto & 149.172 & 76.195 & 1,96 & 2.465 & 1.912 & 42 & 76 \\
Manuel Bandeira & 47.107 & 27.316 & 1,72 & 423 & 399 & 8 & 0 \\
Cecília Meireles & 513.659 & 263.478 & 1,95 & 3.534 & 2.765 & 76 & 150 \\
Graciliano Ramos & 203.094 & 111.017 & 1,83 & 2.693 & 1.996 & 49 & 80 \\
Clarice Lispector & 283.165 & 132.679 & 2,13 & 2.337 & 1.837 & 49 & 66 \\
Erico Verissimo & 227.222 & 111.042 & 2,05 & 2.786 & 1.981 & 45 & 63 \\
Machado de Assis & 143.458 & 79.712 & 1,8 & 3.083 & 2.373 & 45 & 63 \\
Hilda Hilst & 199.292 & 94.461 & 2,11 & 3.346 & 2.479 & 46 & 81 \\
Totais & $\mathbf{2 . 3 8 0 . 6 5 2}$ & $\mathbf{1 . 1 9 1 . 1 4 2}$ & $\mathbf{2 , 0 1}$ & $\mathbf{3 5 . 6 9 8}$ & $\mathbf{2 7 . 0 8 2}$ & $\mathbf{5 8 9}$ & $\mathbf{9 2 1}$ \\
\hline
\end{tabular}

Analisando os dados fornecidos, quais conclusões podem ser tiradas em setembro de 2011 ? Há algum padrão observado? Quais providências você tomaria para atender os objetivos de aumento de produtividade desejados pela diretoria? Qual é a estratégia de segmentação utilizada pela Livraria Cultura? Qual o posicionamento da empresa? Tendo em vista essas estratégias, em que medida suas providências para aumento de produtividade poderiam ferir a proposta de valor da empresa? 
Mesmo depois de tantas análises, as contas não fechavam. Uma loja como Cecília Meireles, apesar de campeã de vendas, vivia muito mais cheia que outras e, com certeza, poderia vender muito mais. Outras, como a Monteiro Lobato, notadamente tinham fluxo muito menor que o da Cecília Meireles, mas chegavam a vender proporcionalmente muito mais.

Havia, ainda, os gerentes das lojas Lima Barreto, Machado de Assis e Mário de Andrade, que reclamavam do baixo fluxo de seus shoppings como justificativa para suas baixas vendas. A pergunta que ficava é: como lojas tão espaçosas, bonitas e localizadas em shoppings perfeitamente adequados ao público-alvo da Livraria Cultura tinham desempenho abaixo da média?

No auge da discussão interna, levantou-se a possibilidade de implantar sistemas de contagem de fluxo. Assim se saberia quantas pessoas entram em cada loja e, confrontando esse número com a quantidade de tickets emitidos, poder-se-ia chegar à taxa de conversão por loja. A primeira ideia para obter esse número seria solicitar aos seguranças de cada loja que registrassem o movimento das pessoas que entrassem na loja com um contador manual. A imprecisão da medida e o estresse desnecessário gerado nesses funcionários fizeram com que esse método fosse rapidamente afastado.

Mas a ideia de contar o número de pessoas que entram na loja era muito interessante. Os diretores da empresa já haviam visto, em feiras no exterior e mesmo no Brasil, empresas com sistemas que permitiam esse tipo de mensuração. A decisão foi chamar três fornecedores, fazer uma cotação e avaliar a possibilidade de implementação do sistema nas lojas da rede.

Após o processo de escolha de fornecedores e da eleição da tecnologia mais adequada, foi realizado um teste piloto, em novembro de 2011. Rapidamente, o sistema foi aprovado, e o roll-out estava pronto em janeiro de 2012, ocasião em que todas as lojas passaram a ter contadores de fluxo de pessoas.

Entre os diversos relatórios proporcionados por esse sistema, estão os que fornecem o fluxo de clientes por hora em cada loja. Na rede, de janeiro a agosto de 2012, o fluxo ficou assim distribuído:

\section{Tabela 2}

Fluxo de clientes por horário e dia da semana (de janeiro a agosto de 2012)

(Observação: Os dados numéricos foram disfarçados. Manteve-se a relação entre eles.)

\begin{tabular}{lrrrrrrrrr}
\hline Horário & Domingo & Segunda & Terça & Quarta & Quinta & Sexta & Sábado & Total & $\begin{array}{r}\text { \% } \\
\text { horário }\end{array}$ \\
9h00 - 10h00 & - & 1.121 & 1.234 & 1.300 & 1.335 & 1.403 & 1.197 & $\mathbf{7 . 5 9 0}$ & $\mathbf{0 , 3 \%}$ \\
$10 \mathrm{~h} 00-11 \mathrm{~h} 00$ & 7 & 12.074 & 12.684 & 13.001 & 13.117 & 14.011 & 19.072 & $\mathbf{8 3 . 9 6 4}$ & $\mathbf{3 , 1 \%}$ \\
11h00 - 12h00 & 7 & 15.691 & 16.376 & 16.304 & 16.919 & 18.388 & 28.458 & $\mathbf{1 1 2 . 1 4 4}$ & $\mathbf{4 , 1 \%}$ \\
12h00 - 13h00 & 9.433 & 26.625 & 28.461 & 27.377 & 27.250 & 28.716 & 33.550 & $\mathbf{1 8 1 . 4 1 2}$ & $\mathbf{6 , 6 \%}$ \\
13h00 - 14h00 & 14.492 & 31.461 & 33.377 & 33.649 & 34.203 & 36.543 & 42.941 & $\mathbf{2 2 6 . 6 6 6}$ & $\mathbf{8 , 3 \%}$ \\
14h00 - 15h00 & 59.143 & 29.627 & 30.547 & 30.510 & 31.825 & 35.332 & 56.122 & $\mathbf{2 7 3 . 1 0 5}$ & $\mathbf{9 , 9 \%}$ \\
15h00 - 16h00 & 67.683 & 30.626 & 30.213 & 30.315 & 31.440 & 36.144 & 66.086 & $\mathbf{2 9 2 . 5 0 7}$ & $\mathbf{1 0 , 7 \%}$ \\
16h00 - 17h00 & 70.362 & 31.263 & 30.576 & 30.933 & 32.257 & 37.370 & 69.387 & $\mathbf{3 0 2 . 1 4 9}$ & $\mathbf{1 1 , 0 \%}$ \\
17h00 - 18h00 & 67.272 & 32.336 & 32.352 & 31.847 & 33.863 & 39.522 & 69.729 & $\mathbf{3 0 6 . 9 2 2}$ & $\mathbf{1 1 , 2 \%}$ \\
18h00 - 19h00 & 61.375 & 34.849 & 35.195 & 35.570 & 37.167 & 43.676 & 65.481 & $\mathbf{3 1 3 . 3 1 2}$ & $\mathbf{1 1 , 4 \%}$ \\
19h00 - 20h00 & 44.590 & 33.987 & 35.313 & 35.895 & 37.531 & 44.453 & 57.914 & $\mathbf{2 8 9 . 6 8 5}$ & $\mathbf{1 0 , 6 \%}$ \\
20h00 - 21h00 & 3.576 & 27.464 & 27.849 & 30.025 & 31.239 & 42.955 & 53.229 & $\mathbf{2 1 6 . 3 3 6}$ & $\mathbf{7 , 9 \%}$ \\
21h00 - 22h00 & 17 & 16.537 & 16.817 & 18.041 & 18.818 & 30.693 & 38.387 & $\mathbf{1 3 9 . 3 1 0}$ & $\mathbf{5 , 1 \%}$ \\
Total Geral & $\mathbf{3 9 7 . 9 5 7}$ & $\mathbf{3 2 3 . 6 6 3}$ & $\mathbf{3 3 0 . 9 9 4}$ & $\mathbf{3 3 4 . 7 6 6}$ & $\mathbf{3 4 6 . 9 6 4}$ & $\mathbf{4 0 9 . 2 0 6}$ & $\mathbf{6 0 1 . 5 5 3}$ & $\mathbf{2 . 7 4 5 . 1 0 3}$ & $\mathbf{1 0 0 , 0 \%}$ \\
\% por dia & $\mathbf{1 4 , 5 \%}$ & $\mathbf{1 1 , 8 \%}$ & $\mathbf{1 2 , 1 \%}$ & $\mathbf{1 2 , 2 \%}$ & $\mathbf{1 2 , 6 \%}$ & $\mathbf{1 4 , 9 \%}$ & $\mathbf{2 1 , 9 \%}$ & $\mathbf{1 0 0 , 0 \%}$ & \\
\hline
\end{tabular}


LIVRARIA CULTURA: ESTÁ BOM, MAS PODERIA ESTAR MELHOR Maurício Gerbaudo Morgado

Graficamente, os dados da Tabela 2 resultam na seguinte figura:

Figura 1

Fluxo de Clientes por Horário e Dia da Semana (Jan-Ago 2012)

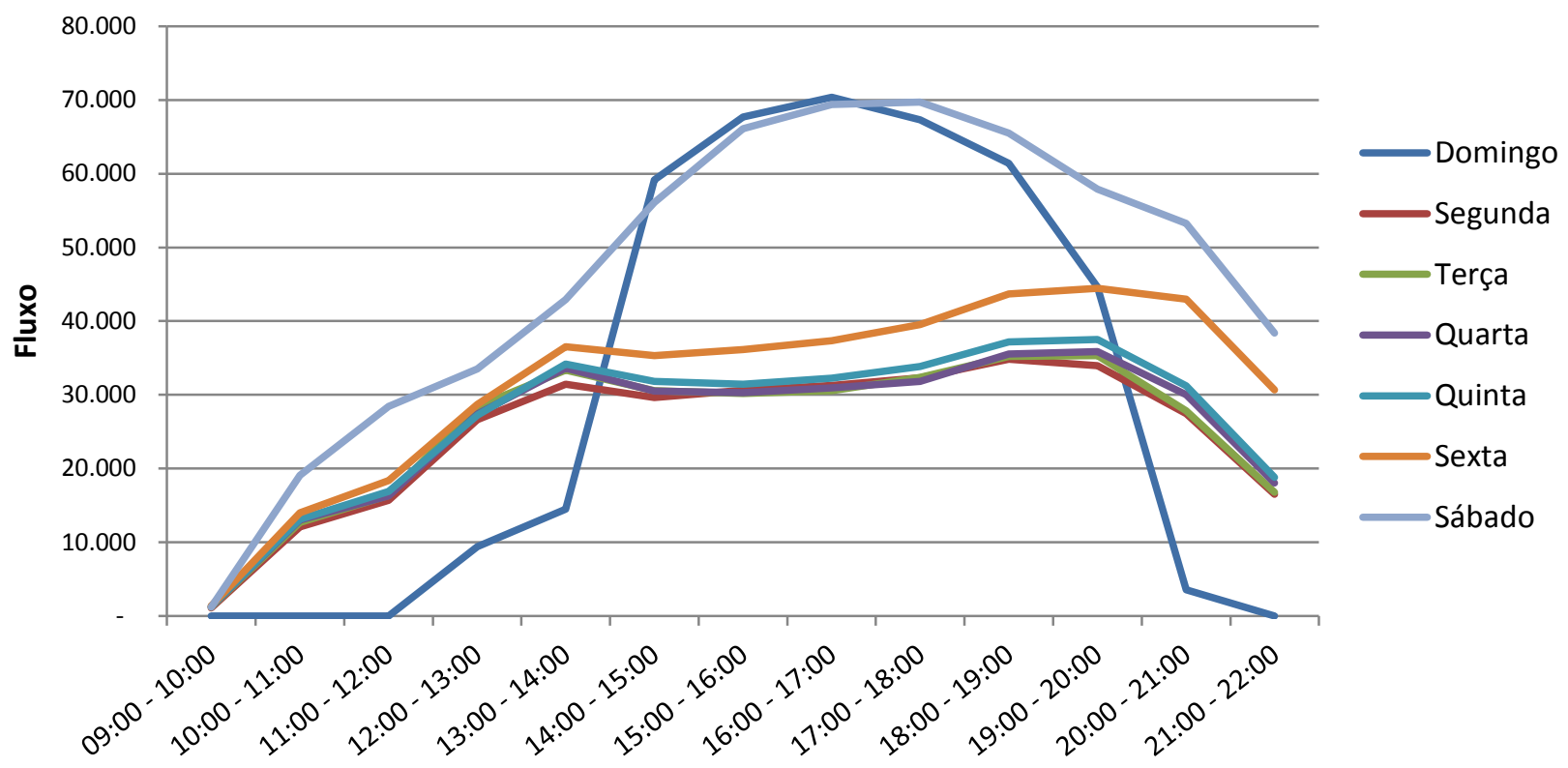

O quadro geral dos dados apresentados vem a seguir.

Tabela 3

Vendas, fluxo, conversão, metragem e número de vendedores (de janeiro a agosto 2012)

(Observação: Os nomes das lojas foram mudados e os dados numéricos disfarçados. Manteve-se a relação entre eles.)

\begin{tabular}{|c|c|c|c|c|c|c|c|c|c|}
\hline $\begin{array}{l}\text { VENDAS } 2012 \\
\text { JAN-AGO }\end{array}$ & $\begin{array}{l}\text { Vendas } \\
\text { em itens }\end{array}$ & $\begin{array}{l}\text { NFs } \\
\text { geradas }\end{array}$ & $\begin{array}{l}\text { Itens por } \\
\text { compra }\end{array}$ & $\begin{array}{l}\text { Fluxo } \\
\text { clientes }\end{array}$ & Conversão & $\begin{array}{l}\text { Metragem } \\
\text { da loja }\end{array}$ & $\begin{array}{l}\text { Área de } \\
\text { vendas }\end{array}$ & $\begin{array}{l}\text { N'ven- } \\
\text { dedores }\end{array}$ & $\begin{array}{l}\text { N. opera- } \\
\text { cionais }\end{array}$ \\
\hline Jorge Amado & 105.532 & 49.226 & 2,14 & 113.867 & $43,2 \%$ & 2.896 & 2.036 & 45 & 63 \\
\hline Mário de Andrade & 92.454 & 49.526 & 1,87 & 168.643 & $29,4 \%$ & 2.715 & 2.033 & 45 & 65 \\
\hline Rubem Fonseca & 72.939 & 40.450 & 1,80 & 130.266 & $31,1 \%$ & 2.731 & 1.977 & 42 & 61 \\
\hline Nelson Rodrigues & 32.004 & 15.593 & 2,05 & 65.387 & $23,8 \%$ & 929 & 791 & 14 & 29 \\
\hline Monteiro Lobato & 84.245 & 41.124 & 2,05 & 94.947 & $43,3 \%$ & 2.052 & 1.644 & 40 & 59 \\
\hline José de Alencar & 102.393 & 51.342 & 1,99 & 132.354 & $38,8 \%$ & 3.709 & 2.857 & 43 & 65 \\
\hline Lima Barreto & 90.410 & 46.973 & 1,92 & 213.307 & $22,0 \%$ & 2.465 & 1.912 & 42 & 76 \\
\hline Manuel Bandeira & 30.758 & 18.685 & 1,65 & 157.756 & $11,8 \%$ & 423 & 399 & 8 & 0 \\
\hline Cecília Meireles & 331.428 & 172.014 & 1,93 & 596.649 & $28,8 \%$ & 3.534 & 2.765 & 76 & 150 \\
\hline Graciliano Ramos & 127.968 & 71.736 & 1,78 & 239.511 & $30,0 \%$ & 2.693 & 1.996 & 49 & 80 \\
\hline Clarice Lispector & 181.569 & 89.105 & 2,04 & 248.223 & $35,9 \%$ & 2.337 & 1.837 & 49 & 66 \\
\hline Erico Verissimo & 144.926 & 72.800 & 1,99 & 206.484 & $35,3 \%$ & 2.786 & 1.981 & 45 & 63 \\
\hline Machado de Assis & 90.972 & 52.622 & 1,73 & 218.402 & $24,1 \%$ & 3.083 & 2.373 & 45 & 63 \\
\hline Hilda Hilst & 113.701 & 56.144 & 2,03 & 159.309 & $35,2 \%$ & 3.346 & 2.479 & 46 & 81 \\
\hline Geral & 1.601.299 & 827.338 & 1,94 & 2.745.105 & $30,1 \%$ & 2.550 & 1.934 & 42 & 66 \\
\hline
\end{tabular}


Com mais informações, novas análises devem ser feitas, confrontando os achados com o que já se sabia antes da implementação do sistema de medição de fluxo de clientes. Assim, novas perguntas se impõem:

- Analisando os dados fornecidos, quais conclusões podem ser tiradas em setembro de 2012 ? Há algum padrão observado? Algo mudou em relação à análise anterior?

- Quais providências você tomaria para atender os objetivos de aumento de produtividade desejados pela diretoria? Algo mudou em relação à análise anterior?

- Em termos de gestão da equipe de loja, a implementação da contagem de fluxo traz algum benefício? Qual?

\section{PARTE 3 - CONFRONTANDO EXTREMOS}

Em junho de 2012, e de posse das novas informações, Rodrigo e Sérgio refizeram suas análises, buscando comparar lojas semelhantes a fim de identificar padrões ou discrepâncias. Por serem muito atípicas em termos de metragem e proposta de negócio, evitaram comparações envolvendo as lojas Manuel Bandeira e Nelson Rodrigues, destacando-as da análise. A tabela a seguir, retratando medidas de produtividade de cada loja, foi produzida:

\section{Tabela 4}

\section{Medidas de produtividade por loja}

\begin{tabular}{lcccc}
\hline Vendas jan-ago 2012 & Itens por compra & Conversão & $\begin{array}{c}\text { Fluxo } \\
\text { por vendedor }\end{array}$ & $\begin{array}{c}\text { Área vendas } \\
\text { por vendedor }\end{array}$ \\
Monteiro Lobato & 2,05 & $43,3 \%$ & 2.316 & 41 \\
Jorge Amado & 2,14 & $43,2 \%$ & 2.530 & 45 \\
José de Alencar & 1,99 & $38,8 \%$ & 2.005 & 66 \\
Clarice Lispector & 2,04 & $35,9 \%$ & 6.709 & 37 \\
Erico Verissimo & 1,99 & $35,3 \%$ & 4.693 & 44 \\
Hilda Hilst & 2,03 & $35,2 \%$ & 2.950 & 54 \\
Rubem Fonseca & 1,8 & $31,1 \%$ & 2.772 & 47 \\
Graciliano Ramos & 1,78 & $30,0 \%$ & 5.842 & 41 \\
Mário de Andrade & 1,87 & $29,4 \%$ & 3.748 & 45 \\
Cecília Meireles & 1,93 & $28,8 \%$ & 16.574 & 36 \\
Machado de Assis & 1,73 & $24,1 \%$ & 4.121 & 53 \\
Lima Barreto & 1,92 & $22,0 \%$ & 4.637 & 46 \\
Média & 1,94 & $33,1 \%$ & 4.908 & 46 \\
\hline
\end{tabular}

Analisando somente a taxa de conversão, a loja Monteiro Lobato era o destaque positivo. No outro extremo, destacando-se pelo inverso, estava a loja Lima Barreto, convertendo praticamente metade do que a outra convertia. Para agravar ainda mais a situação da segunda, essa recebia um fluxo 65,5\% maior do que a primeira. A favor da loja Lima Barreto, seria possível dizer que ela teria menos vendedores para cobrir a área de vendas, mas, mesmo assim, essa diferença não era tão grande a ponto de justificar tamanha discrepância.

Solicitaram ao fornecedor do sistema de medição de fluxo relatórios mais detalhados sobre essas duas lojas. Os relatórios fornecidos estão reproduzidos nas páginas 9 a 12. Que análises podem ser feitas confrontando esses dados? O que a loja Lima Barreto e a empresa, como um todo, podem aprender com a loja Monteiro Lobato? 


\section{Monteiro Lobato - relatórios detalhados de fluxo}

Monteiro Lobato: fluxo, cupons emitidos e taxa de conversão

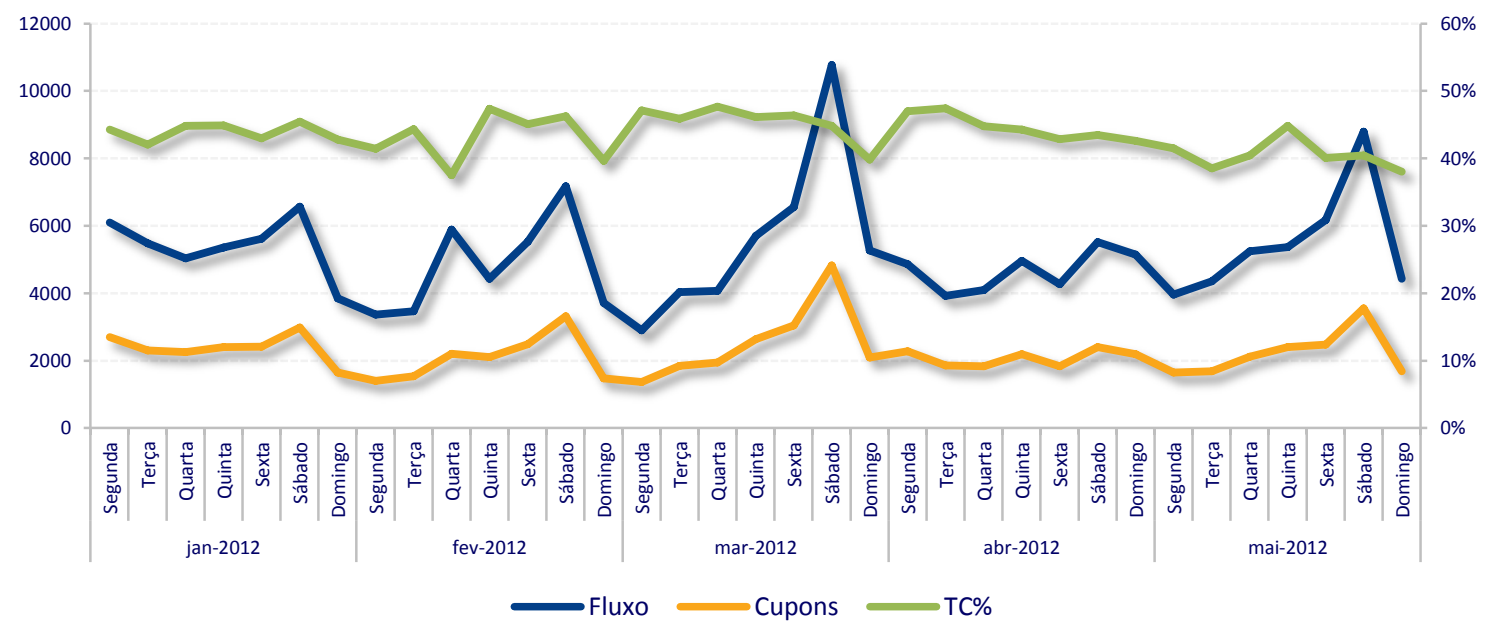

Monteiro Lobato: horas quentes semanais

\begin{tabular}{|c|c|c|c|c|c|c|c|}
\hline \multicolumn{8}{|c|}{$\mathrm{mar} / 12$} \\
\hline Faixa & Segunda & Terça & Quarta & Quinta & Sexta & Sábado & Domingo \\
\hline $10: 00-11: 00$ & 63 & 70 & 74 & 83 & 90 & 154 & - \\
\hline $11: 00-12: 00$ & 62 & 54 & 64 & 70 & 74 & 143 & -- \\
\hline $12: 00-13: 00$ & 67 & 54 & 63 & 67 & 78 & 113 & - \\
\hline $13: 00-14: 00$ & 62 & 71 & 62 & 82 & 67 & 109 & -- \\
\hline $14: 00-15: 00$ & 70 & 67 & 68 & 72 & 84 & 161 & - \\
\hline $15: 00-16: 00$ & 77 & 76 & 85 & 93 & 104 & 188 & 300 \\
\hline $16: 00-17: 00$ & 115 & 102 & 102 & 104 & 120 & 227 & 240 \\
\hline $17: 00-18: 00$ & 103 & 114 & 110 & 133 & 143 & 281 & 246 \\
\hline $18: 00-19: 00$ & 110 & 116 & 126 & 164 & 176 & 269 & 250 \\
\hline $19: 00-20: 00$ & 108 & 146 & 124 & 129 & 177 & 227 & 182 \\
\hline $20: 00-21: 00$ & 91 & 98 & 91 & 98 & 128 & 202 & 100 \\
\hline $21: 00-22: 00$ & 38 & 38 & 49 & 45 & 71 & 80 & - \\
\hline TOTAL & 966 & 1007 & 1017 & 1141 & 1312 & 2155 & 1318 \\
\hline
\end{tabular}

\begin{tabular}{|c|c|c|c|c|c|c|c|}
\hline \multicolumn{8}{|c|}{$\mathrm{abr} / 12$} \\
\hline Faixa & Segunda & Terça & Quarta & Quinta & Sexta & Sábado & Domingo \\
\hline $10: 00-11: 00$ & 69 & 70 & 82 & 78 & 85 & 128 & - \\
\hline $11: 00-12: 00$ & 51 & 72 & 66 & 63 & 67 & 128 & - \\
\hline $12: 00-13: 00$ & 62 & 62 & 57 & 60 & 67 & 90 & -- \\
\hline $13: 00-14: 00$ & 47 & 60 & 70 & 66 & 71 & 83 & -- \\
\hline $14: 00-15: 00$ & 60 & 72 & 72 & 87 & 100 & 121 & - \\
\hline $15: 00-16: 00$ & 85 & 84 & 78 & 96 & 114 & 156 & 206 \\
\hline $16: 00-17: 00$ & 101 & 77 & 98 & 136 & 134 & 213 & 180 \\
\hline $17: 00-18: 00$ & 111 & 105 & 104 & 174 & 152 & 256 & 196 \\
\hline $18: 00-19: 00$ & 136 & 130 & 144 & 191 & 205 & 256 & 198 \\
\hline $19: 00-20: 00$ & 111 & 126 & 121 & 134 & 207 & 195 & 169 \\
\hline $20: 00-21: 00$ & 104 & 87 & 87 & 103 & 132 & 141 & 79 \\
\hline $21: 00-22: 00$ & 37 & 35 & 43 & 52 & 89 & 71 & - \\
\hline TOTAL & 972 & 980 & 1022 & 1239 & 1421 & 1838 & 1028 \\
\hline
\end{tabular}

\begin{tabular}{|c|c|c|c|c|c|c|c|}
\hline \multicolumn{8}{|c|}{$\mathrm{mai} / 12$} \\
\hline Faixa & Segunda & Terça & Quarta & Quinta & Sexta & Sábado & Domingo \\
\hline $10: 00-11: 00$ & 65 & 78 & 66 & 77 & 78 & 134 & - \\
\hline $11: 00-12: 00$ & 62 & 56 & 62 & 56 & 64 & 137 & -- \\
\hline $12: 00-13: 00$ & 62 & 54 & 57 & 47 & 56 & 94 & - \\
\hline $13: 00-14: 00$ & 65 & 64 & 63 & 67 & 75 & 110 & -- \\
\hline $14: 00-15: 00$ & 71 & 66 & 65 & 72 & 82 & 158 & -- \\
\hline $15: 00-16: 00$ & 70 & 72 & 84 & 90 & 110 & 188 & 192 \\
\hline $16: 00-17: 00$ & 93 & 103 & 99 & 102 & 188 & 246 & 213 \\
\hline $17: 00-18: 00$ & 116 & 133 & 131 & 135 & 204 & 307 & 212 \\
\hline $18: 00-19: 00$ & 145 & 192 & 164 & 159 & 235 & 268 & 229 \\
\hline $19: 00-20: 00$ & 109 & 145 & 133 & 134 & 207 & 254 & 172 \\
\hline $20: 00-21: 00$ & 88 & 84 & 85 & 92 & 164 & 201 & 90 \\
\hline $21: 00-22: 00$ & 44 & 42 & 40 & 43 & 82 & 98 & - \\
\hline TOTAL & 991 & 1090 & 1049 & 1074 & 1544 & 2198 & 1108 \\
\hline
\end{tabular}


LIVRARIA CULTURA: ESTÁ BOM, MAS PODERIA ESTAR MELHOR

Maurício Gerbaudo Morgado

Monteiro Lobato - horas quentes diárias

\begin{tabular}{|c|c|c|c|c|c|c|c|}
\hline \multicolumn{8}{|c|}{$\mathrm{mar} / 12$} \\
\hline Faixa & Segunda & Terça & Quarta & Quinta & Sexta & Sábado & Domingo \\
\hline $10: 00-11: 00$ & 63 & 70 & 74 & 83 & 90 & 154 & - \\
\hline $11: 00-12: 00$ & 62 & 54 & 64 & 70 & 74 & 143 & - \\
\hline $12: 00-13: 00$ & 67 & 54 & 63 & 67 & 78 & 113 & - \\
\hline $13: 00-14: 00$ & 62 & 71 & 62 & 82 & 67 & 109 & -- \\
\hline $14: 00-15: 00$ & 70 & 67 & 68 & 72 & 84 & 161 & - \\
\hline $15: 00-16: 00$ & 77 & 76 & 85 & 93 & 104 & 188 & 300 \\
\hline $16: 00-17: 00$ & 115 & 102 & 102 & 104 & 120 & 227 & 240 \\
\hline $17: 00-18: 00$ & 103 & 114 & 110 & 133 & 143 & 281 & 246 \\
\hline $18: 00-19: 00$ & 110 & 116 & 126 & 164 & 176 & 269 & 250 \\
\hline $19: 00-20: 00$ & 108 & 146 & 124 & 129 & 177 & 227 & 182 \\
\hline $20: 00-21: 00$ & 91 & 98 & 91 & 98 & 128 & 202 & 100 \\
\hline $21: 00-22: 00$ & 38 & 38 & 49 & 45 & 71 & 80 & - \\
\hline TOTAL & 966 & 1007 & 1017 & 1141 & 1312 & 2155 & 1318 \\
\hline
\end{tabular}

\begin{tabular}{|c|c|c|c|c|c|c|c|}
\hline \multicolumn{8}{|c|}{$\mathrm{abr} / 12$} \\
\hline Faixa & Segunda & Terça & Quarta & Quinta & Sexta & Sábado & Domingo \\
\hline $10: 00-11: 00$ & 69 & 70 & 82 & 78 & 85 & 128 & - \\
\hline $11: 00-12: 00$ & 51 & 72 & 66 & 63 & 67 & 128 & -- \\
\hline $12: 00-13: 00$ & 62 & 62 & 57 & 60 & 67 & 90 & -- \\
\hline $13: 00-14: 00$ & 47 & 60 & 70 & 66 & 71 & 83 & - \\
\hline $14: 00-15: 00$ & 60 & 72 & 72 & 87 & 100 & 121 & - \\
\hline $15: 00-16: 00$ & 85 & 84 & 78 & 96 & 114 & 156 & 206 \\
\hline $16: 00-17: 00$ & 101 & 77 & 98 & 136 & 134 & 213 & 180 \\
\hline $17: 00-18: 00$ & 111 & 105 & 104 & 174 & 152 & 256 & 196 \\
\hline $18: 00-19: 00$ & 136 & 130 & 144 & 191 & 205 & 256 & 198 \\
\hline $19: 00-20: 00$ & 111 & 126 & 121 & 134 & 207 & 195 & 169 \\
\hline $20: 00-21: 00$ & 104 & 87 & 87 & 103 & 132 & 141 & 79 \\
\hline $21: 00-22: 00$ & 37 & 35 & 43 & 52 & 89 & 71 & - \\
\hline TOTAL & 972 & 980 & 1022 & 1239 & 1421 & 1838 & 1028 \\
\hline
\end{tabular}

\begin{tabular}{|c|c|c|c|c|c|c|c|}
\hline \multicolumn{8}{|c|}{$\mathrm{mai} / 12$} \\
\hline Faixa & \begin{tabular}{|l|} 
Segunda \\
\end{tabular} & Terça & Quarta & Quinta & Sexta & Sábado & Domingo \\
\hline $10: 00-11: 00$ & 65 & 78 & 66 & 77 & 78 & 134 & - \\
\hline $11: 00-12: 00$ & 62 & 56 & 62 & 56 & 64 & 137 & -- \\
\hline $12: 00-13: 00$ & 62 & 54 & 57 & 47 & 56 & 94 & -- \\
\hline $13: 00-14: 00$ & 65 & 64 & 63 & 67 & 75 & 110 & -- \\
\hline $14: 00-15: 00$ & 71 & 66 & 65 & 72 & 82 & 158 & -- \\
\hline $15: 00-16: 00$ & 70 & 72 & 84 & 90 & 110 & 188 & 192 \\
\hline $16: 00-17: 00$ & 93 & 103 & 99 & 102 & 188 & 246 & 213 \\
\hline $17: 00-18: 00$ & 116 & 133 & 131 & 135 & 204 & 307 & 212 \\
\hline $18: 00-19: 00$ & 145 & 192 & 164 & 159 & 235 & 268 & 229 \\
\hline $19: 00-20: 00$ & 109 & 145 & 133 & 134 & 207 & 254 & 172 \\
\hline $20: 00-21: 00$ & 88 & 84 & 85 & 92 & 164 & 201 & 90 \\
\hline $21: 00-22: 00$ & 44 & 42 & 40 & 43 & 82 & 98 & - \\
\hline TOTAL & 991 & 1090 & 1049 & 1074 & 1544 & 2198 & 1108 \\
\hline
\end{tabular}




\section{Lima Barreto - relatórios detalhados de fluxo}

Lima Barreto - fluxo, cupons emitidos e taxa de conversão

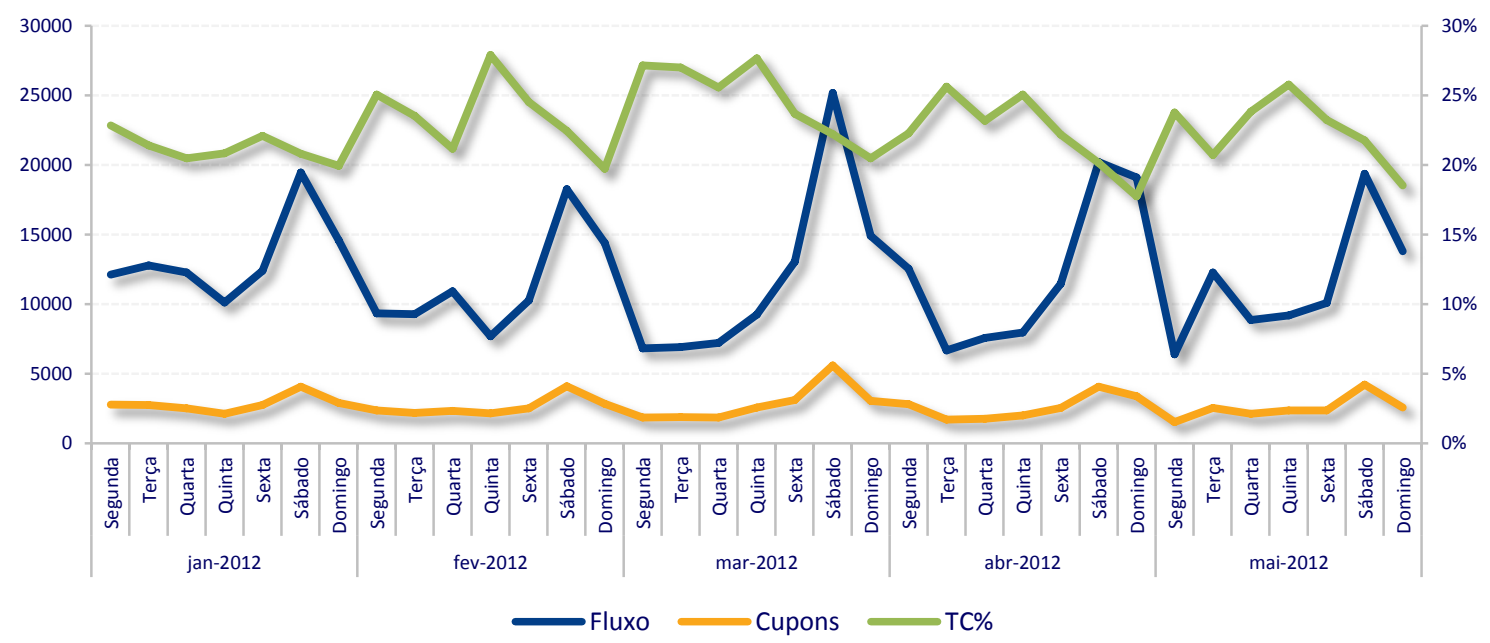

Lima Barreto - horas quentes semanais

\begin{tabular}{|c|c|c|c|c|c|c|c|}
\hline \multicolumn{8}{|c|}{$\mathrm{mar} / 12$} \\
\hline Faixa & Segunda & Terça & Quarta & Quinta & Sexta & Sábado & Domingo \\
\hline $10: 00-11: 00$ & 67 & 74 & 71 & 70 & 64 & 83 & - \\
\hline $11: 00-12: 00$ & 81 & 88 & 87 & 81 & 88 & 165 & -- \\
\hline $12: 00-13: 00$ & 204 & 205 & 203 & 203 & 204 & 218 & 148 \\
\hline $13: 00-14: 00$ & 247 & 248 & 264 & 269 & 276 & 336 & 358 \\
\hline $14: 00-15: 00$ & 169 & 174 & 172 & 184 & 219 & 501 & 592 \\
\hline $15: 00-16: 00$ & 131 & 114 & 138 & 149 & 195 & 557 & 600 \\
\hline $16: 00-17: 00$ & 125 & 132 & 147 & 141 & 201 & 556 & 642 \\
\hline $17: 00-18: 00$ & 134 & 132 & 148 & 145 & 224 & 572 & 528 \\
\hline $18: 00-19: 00$ & 157 & 156 & 148 & 184 & 263 & 521 & 481 \\
\hline $19: 00-20: 00$ & 160 & 170 & 171 & 175 & 289 & 522 & 373 \\
\hline $20: 00-21: 00$ & 146 & 130 & 153 & 137 & 329 & 541 & - \\
\hline $21: 00-22: 00$ & 86 & 102 & 96 & 109 & 258 & 464 & - \\
\hline TOTAL & 1707 & 1727 & 1800 & 1847 & 2610 & 5036 & 3723 \\
\hline
\end{tabular}

\begin{tabular}{|c|c|c|c|c|c|c|c|}
\hline \multicolumn{8}{|c|}{$a b r / 12$} \\
\hline Faixa & \begin{tabular}{|l|} 
Segunda \\
\end{tabular} & Terça & Quarta & Quinta & Sexta & Sábado & Domingo \\
\hline $10: 00-11: 00$ & 57 & 66 & 71 & 59 & 52 & 54 & - \\
\hline $11: 00-12: 00$ & 90 & 84 & 81 & 92 & 97 & 129 & -- \\
\hline $12: 00-13: 00$ & 230 & 184 & 170 & 184 & 177 & 227 & 164 \\
\hline $13: 00-14: 00$ & 299 & 270 & 285 & 275 & 283 & 387 & 385 \\
\hline $14: 00-15: 00$ & 241 & 189 & 194 & 202 & 265 & 547 & 597 \\
\hline $15: 00-16: 00$ & 256 & 118 & 134 & 134 & 273 & 626 & 634 \\
\hline $16: 00-17: 00$ & 248 & 124 & 168 & 148 & 262 & 642 & 618 \\
\hline $17: 00-18: 00$ & 271 & 125 & 150 & 166 & 303 & 638 & 628 \\
\hline $18: 00-19: 00$ & 234 & 146 & 181 & 202 & 348 & 588 & 468 \\
\hline $19: 00-20: 00$ & 224 & 143 & 186 & 202 & 333 & 490 & 321 \\
\hline $20: 00-21: 00$ & 220 & 137 & 158 & 203 & 380 & 410 & - \\
\hline $21: 00-22: 00$ & 135 & 82 & 111 & 122 & 293 & 310 & - \\
\hline TOTAL & 2505 & 1665 & 1889 & 1990 & 3068 & 5047 & 3815 \\
\hline
\end{tabular}

\begin{tabular}{|c|c|c|c|c|c|c|c|}
\hline \multicolumn{8}{|c|}{$\mathrm{mai} / 12$} \\
\hline Faixa & \begin{tabular}{|l|} 
Segunda \\
\end{tabular} & Terça & Quarta & Quinta & Sexta & Sábado & Domingo \\
\hline $10: 00-11: 00$ & 58 & 71 & 56 & 56 & 62 & 79 & - \\
\hline $11: 00-12: 00$ & 66 & 66 & 75 & 78 & 85 & 162 & -- \\
\hline $12: 00-13: 00$ & 178 & 206 & 164 & 205 & 177 & 212 & 133 \\
\hline $13: 00-14: 00$ & 269 & 307 & 273 & 284 & 275 & 303 & 348 \\
\hline $14: 00-15: 00$ & 183 & 280 & 180 & 192 & 220 & 468 & 545 \\
\hline $15: 00-16: 00$ & 123 & 289 & 154 & 145 & 200 & 534 & 544 \\
\hline $16: 00-17: 00$ & 131 & 296 & 139 & 139 & 188 & 578 & 616 \\
\hline $17: 00-18: 00$ & 123 & 280 & 155 & 142 & 194 & 551 & 513 \\
\hline $18: 00-19: 00$ & 144 & 263 & 165 & 166 & 250 & 547 & 453 \\
\hline $19: 00-20: 00$ & 112 & 226 & 169 & 173 & 270 & 449 & 296 \\
\hline $20: 00-21: 00$ & 132 & 139 & 151 & 151 & 325 & 540 & -- \\
\hline $21: 00-22: 00$ & 76 & 104 & 91 & 102 & 274 & 414 & -- \\
\hline TOTAL & 1596 & 2526 & 1773 & 1833 & 2521 & 4838 & 3449 \\
\hline
\end{tabular}


LIVRARIA CULTURA: ESTÁ BOM, MAS PODERIA ESTAR MELHOR

Maurício Gerbaudo Morgado

\section{Lima Barreto - horas quentes diárias}

\begin{tabular}{|c|c|c|c|c|c|c|c|}
\hline \multicolumn{8}{|c|}{$\mathrm{mar} / 12$} \\
\hline Faixa & Segunda & Terça & Quarta & Quinta & Sexta & Sábado & Domingo \\
\hline $10: 00-11: 00$ & 67 & 74 & 71 & 70 & 64 & 83 & - \\
\hline $11: 00-12: 00$ & 81 & 88 & 87 & 81 & 88 & 165 & - \\
\hline $12: 00-13: 00$ & 204 & 205 & 203 & 203 & 204 & 218 & 148 \\
\hline $13: 00-14: 00$ & 247 & 248 & 264 & 269 & 276 & 336 & 358 \\
\hline $14: 00-15: 00$ & 169 & 174 & 172 & 184 & 219 & 501 & 592 \\
\hline $15: 00-16: 00$ & 131 & 114 & 138 & 149 & 195 & 557 & 600 \\
\hline $16: 00-17: 00$ & 125 & 132 & 147 & 141 & 201 & 556 & 642 \\
\hline $17: 00-18: 00$ & 134 & 132 & 148 & 145 & 224 & 572 & 528 \\
\hline $18: 00-19: 00$ & 157 & 156 & 148 & 184 & 263 & 521 & 481 \\
\hline $19: 00-20: 00$ & 160 & 170 & 171 & 175 & 289 & 522 & 373 \\
\hline $20: 00-21: 00$ & 146 & 130 & 153 & 137 & 329 & 541 & - \\
\hline $21: 00-22: 00$ & 86 & 102 & 96 & 109 & 258 & 464 & - \\
\hline TOTAL & 1707 & 1727 & 1800 & 1847 & 2610 & 5036 & 3723 \\
\hline
\end{tabular}

\begin{tabular}{|c|c|c|c|c|c|c|c|}
\hline \multicolumn{8}{|c|}{$\mathrm{abr} / 12$} \\
\hline Faixa & Segunda & Terça & Quarta & Quinta & Sexta & Sábado & Domingo \\
\hline $10: 00-11: 00$ & 57 & 66 & 71 & 59 & 52 & 54 & -- \\
\hline $11: 00-12: 00$ & 90 & 84 & 81 & 92 & 97 & 129 & -- \\
\hline $12: 00-13: 00$ & 230 & 184 & 170 & 184 & 177 & 227 & 164 \\
\hline $13: 00-14: 00$ & 299 & 270 & 285 & 275 & 283 & 387 & 385 \\
\hline $14: 00-15: 00$ & 241 & 189 & 194 & 202 & 265 & 547 & 597 \\
\hline $15: 00-16: 00$ & 256 & 118 & 134 & 134 & 273 & 626 & 634 \\
\hline $16: 00-17: 00$ & 248 & 124 & 168 & 148 & 262 & 642 & 618 \\
\hline $17: 00-18: 00$ & 271 & 125 & 150 & 166 & 303 & 638 & 628 \\
\hline $18: 00-19: 00$ & 234 & 146 & 181 & 202 & 348 & 588 & 468 \\
\hline $19: 00-20: 00$ & 224 & 143 & 186 & 202 & 333 & 490 & 321 \\
\hline $20: 00-21: 00$ & 220 & 137 & 158 & 203 & 380 & 410 & - \\
\hline $21: 00-22: 00$ & 135 & 82 & 111 & 122 & 293 & 310 & -- \\
\hline TOTAL & 2505 & 1665 & 1889 & 1990 & 3068 & 5047 & 3815 \\
\hline
\end{tabular}

\begin{tabular}{|c|c|c|c|c|c|c|c|}
\hline \multicolumn{8}{|c|}{$\mathrm{mai} / 12$} \\
\hline Faixa & Segunda & Terça & Quarta & Quinta & Sexta & Sábado & Domingo \\
\hline $10: 00-11: 00$ & 58 & 71 & 56 & 56 & 62 & 79 & - \\
\hline $11: 00-12: 00$ & 66 & 66 & 75 & 78 & 85 & 162 & -- \\
\hline $12: 00-13: 00$ & 178 & 206 & 164 & 205 & 177 & 212 & 133 \\
\hline $13: 00-14: 00$ & 269 & 307 & 273 & 284 & 275 & 303 & 348 \\
\hline $14: 00-15: 00$ & 183 & 280 & 180 & 192 & 220 & 468 & 545 \\
\hline $15: 00-16: 00$ & 123 & 289 & 154 & 145 & 200 & 534 & 544 \\
\hline $16: 00-17: 00$ & 131 & 296 & 139 & 139 & 188 & 578 & 616 \\
\hline $17: 00-18: 00$ & 123 & 280 & 155 & 142 & 194 & 551 & 513 \\
\hline $18: 00-19: 00$ & 144 & 263 & 165 & 166 & 250 & 547 & 453 \\
\hline $19: 00-20: 00$ & 112 & 226 & 169 & 173 & 270 & 449 & 296 \\
\hline $20: 00-21: 00$ & 132 & 139 & 151 & 151 & 325 & 540 & - \\
\hline $21: 00-22: 00$ & 76 & 104 & 91 & 102 & 274 & 414 & -- \\
\hline TOTAL & 1596 & 2526 & 1773 & 1833 & 2521 & 4838 & 3449 \\
\hline
\end{tabular}


LIVRARIA CULTURA: ESTÁ BOM, MAS PODERIA ESTAR MELHOR Maurício Gerbaudo Morgado

\section{ANEXOS}

\section{Anexo 1 \\ Fotos da Livraria Cultura}

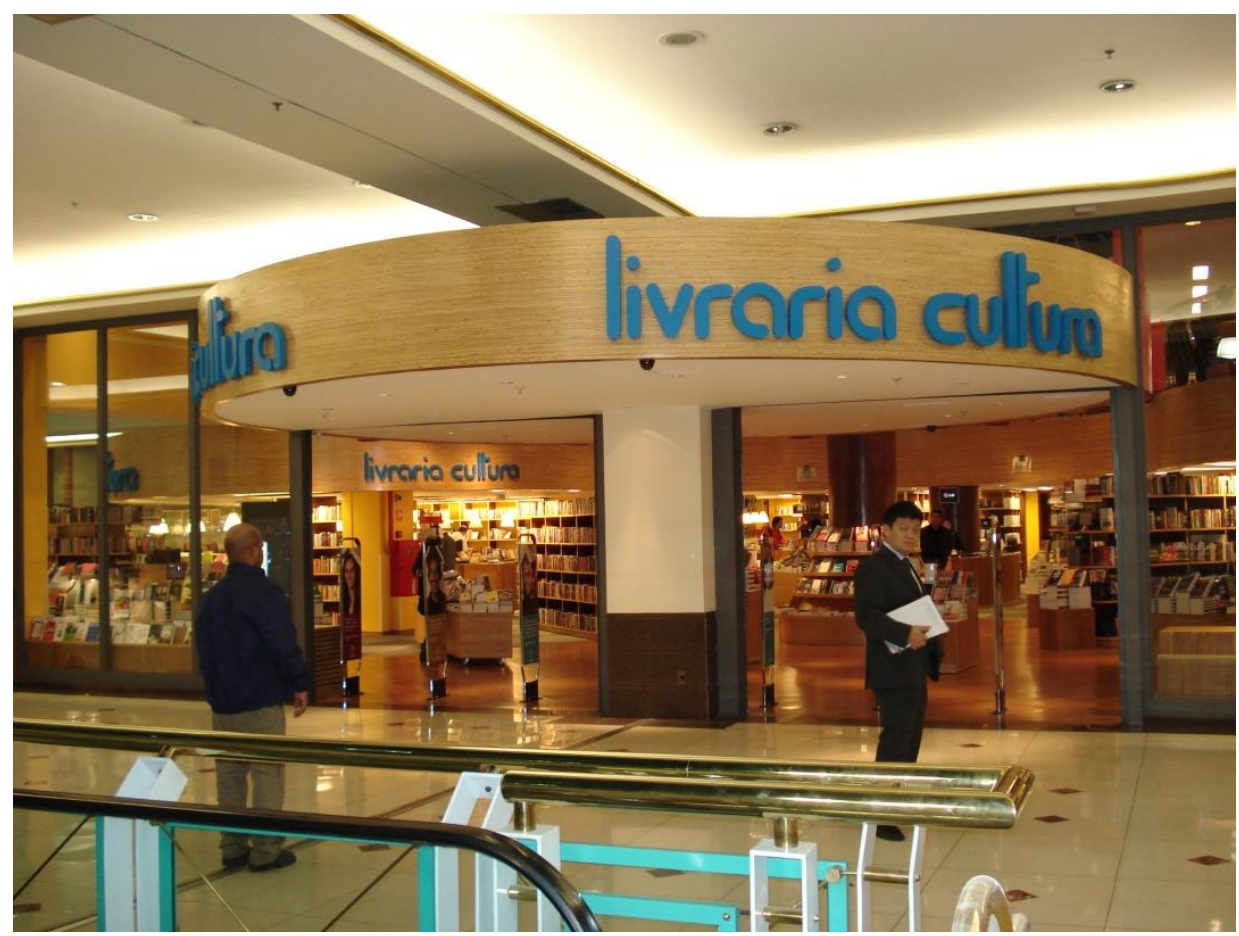

Fachada loja Market Place

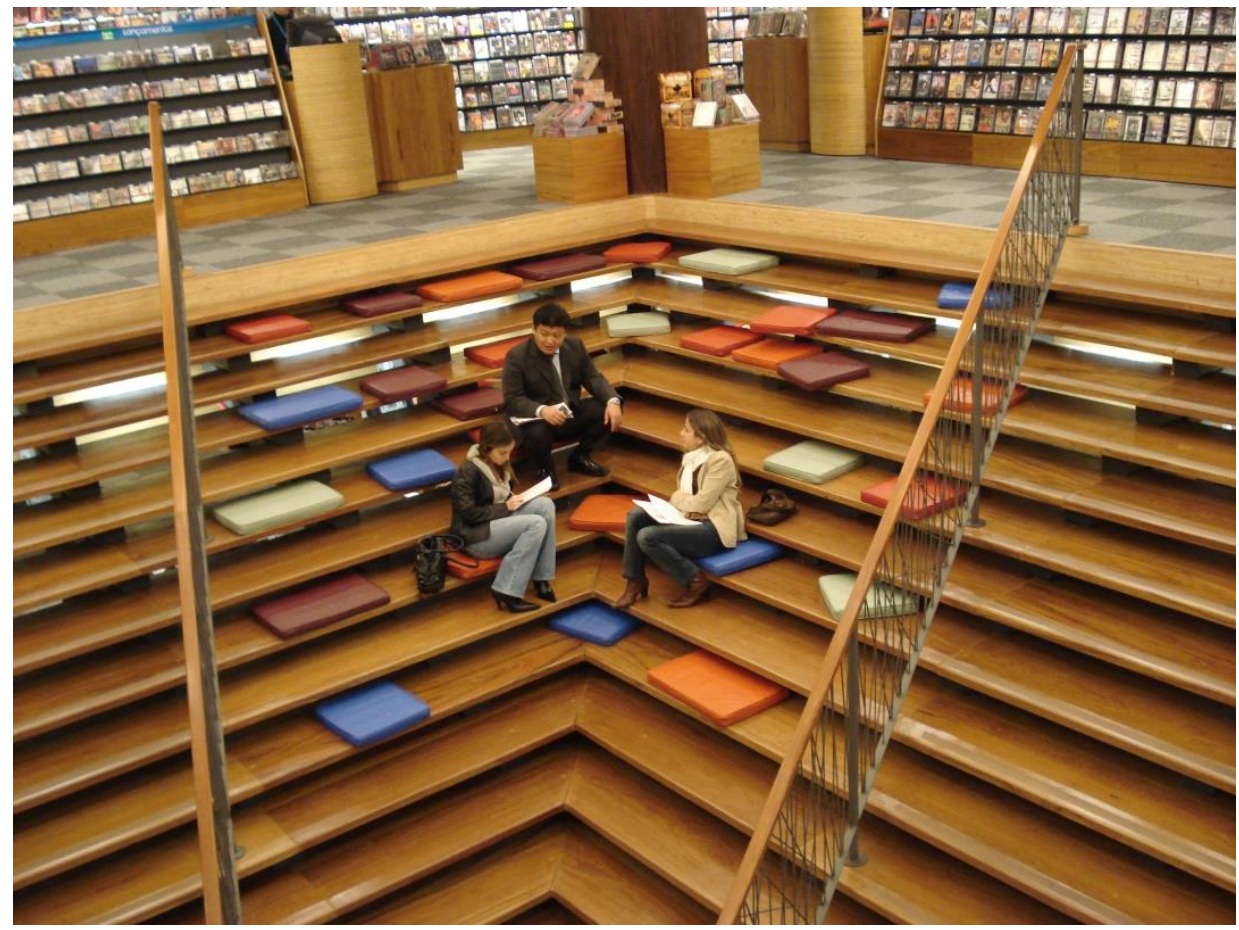

Escadaria da loja Market Place 
LIVRARIA CULTURA: ESTÁ BOM, MAS PODERIA ESTAR MELHOR Maurício Gerbaudo Morgado

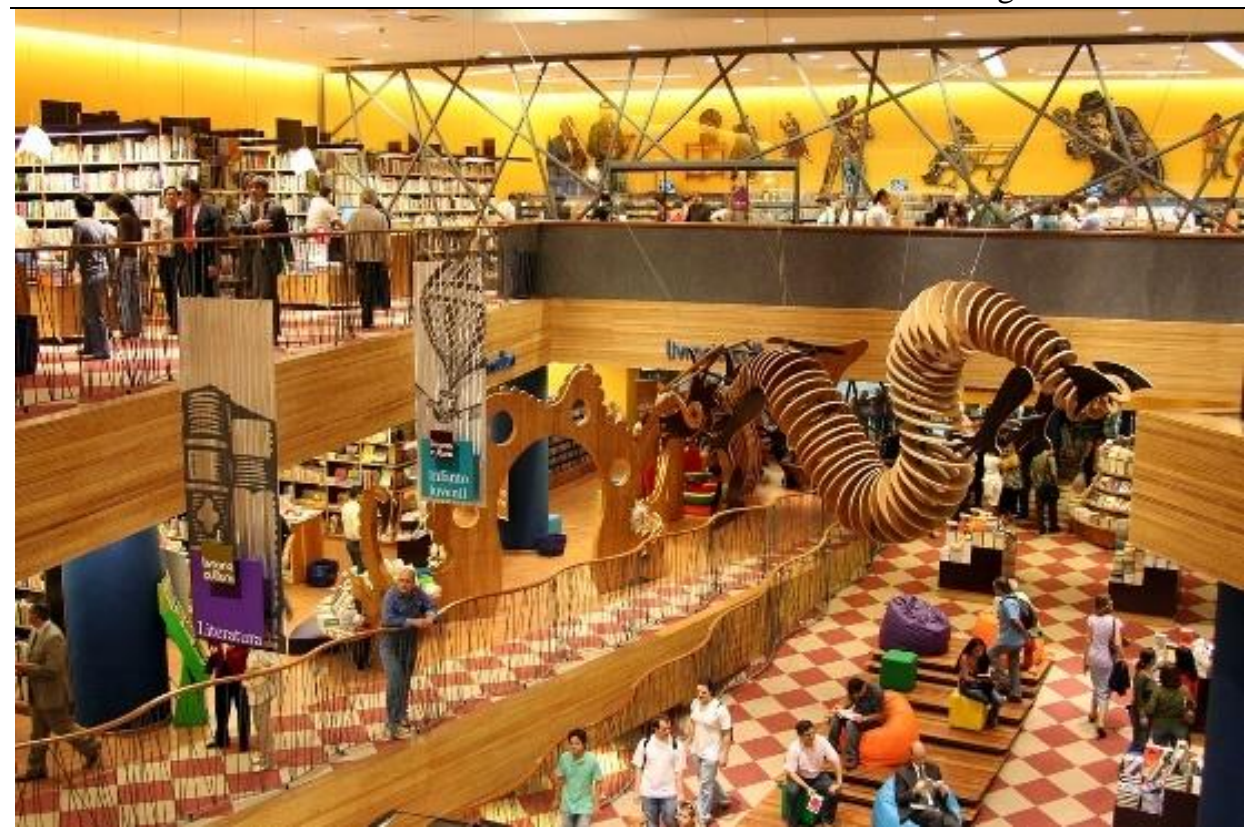

Interior da loja Paulista Cine Astor

(Imagem reproduzida de http://tempointegral.wordpress.com/tag/livraria-cultura/)

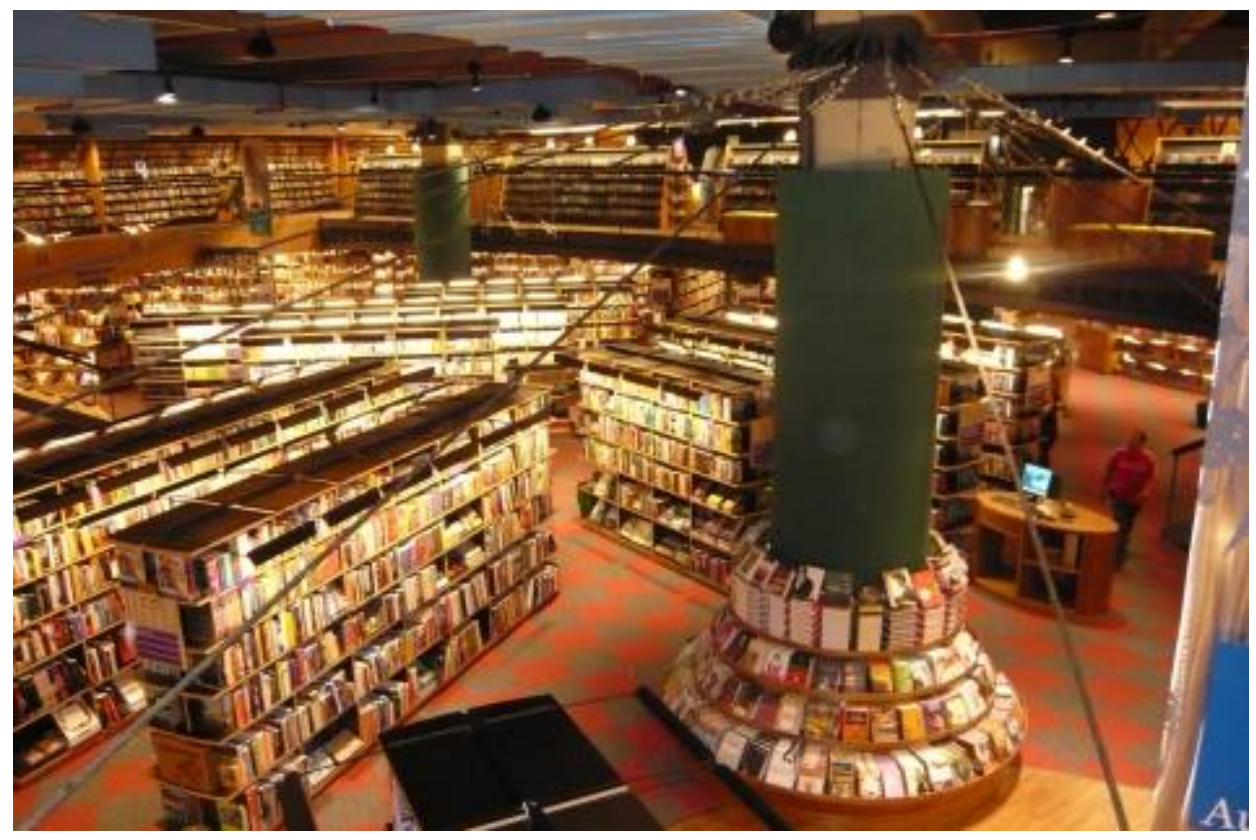

Interior de uma loja

(Imagem reproduzida de http://www.tocadacotia.com/cultura/a-incrivel-historia-da-livraria-cultura) 
LIVRARIA CULTURA: ESTÁ BOM, MAS PODERIA ESTAR MELHOR Maurício Gerbaudo Morgado

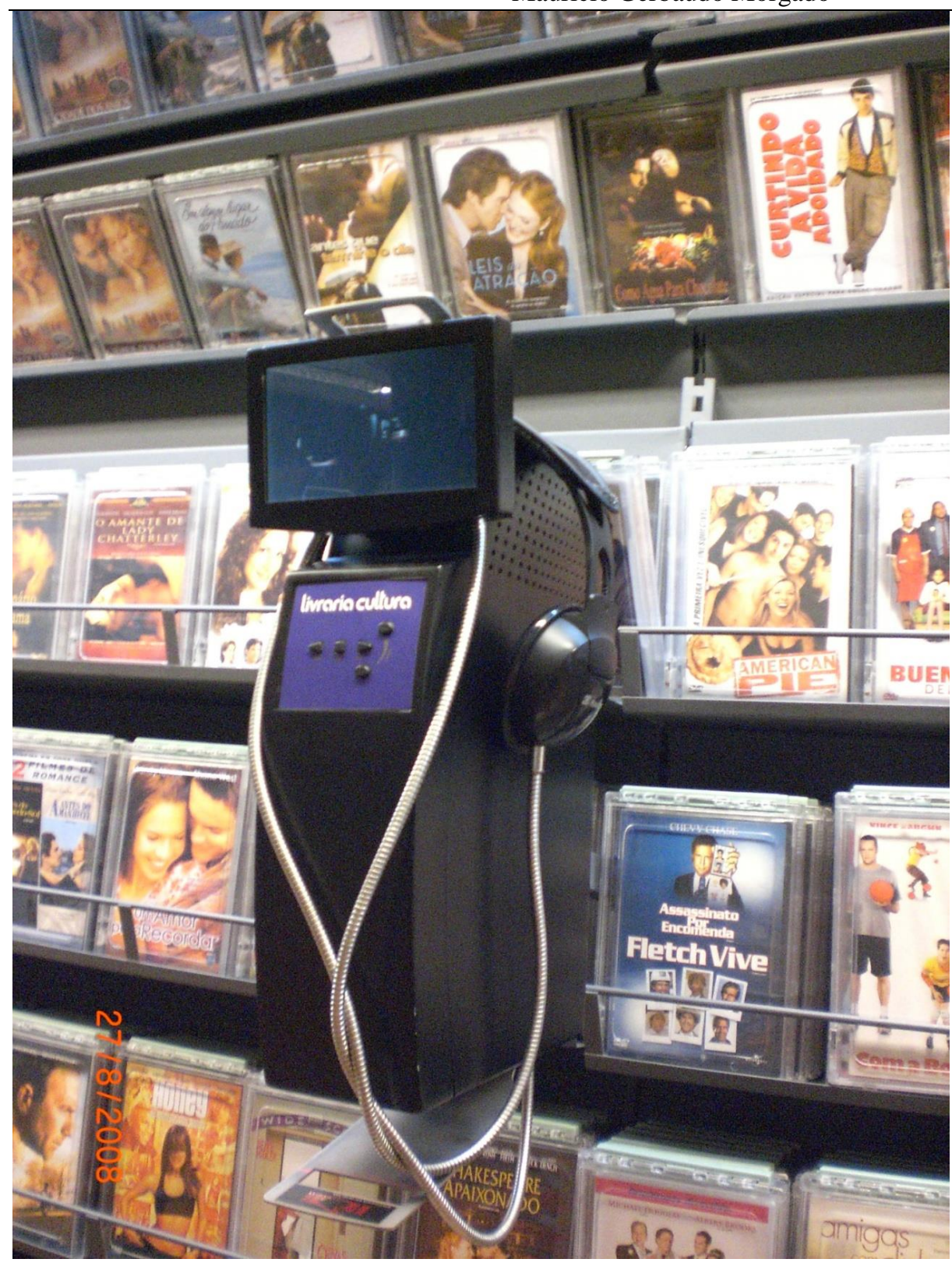

Equipamento para exibição de trechos de filmes 
LIVRARIA CULTURA: ESTÁ BOM, MAS PODERIA ESTAR MELHOR Maurício Gerbaudo Morgado

\section{Anexo 2}

Desempenho do varejo de livros, jornais, revistas e papelaria

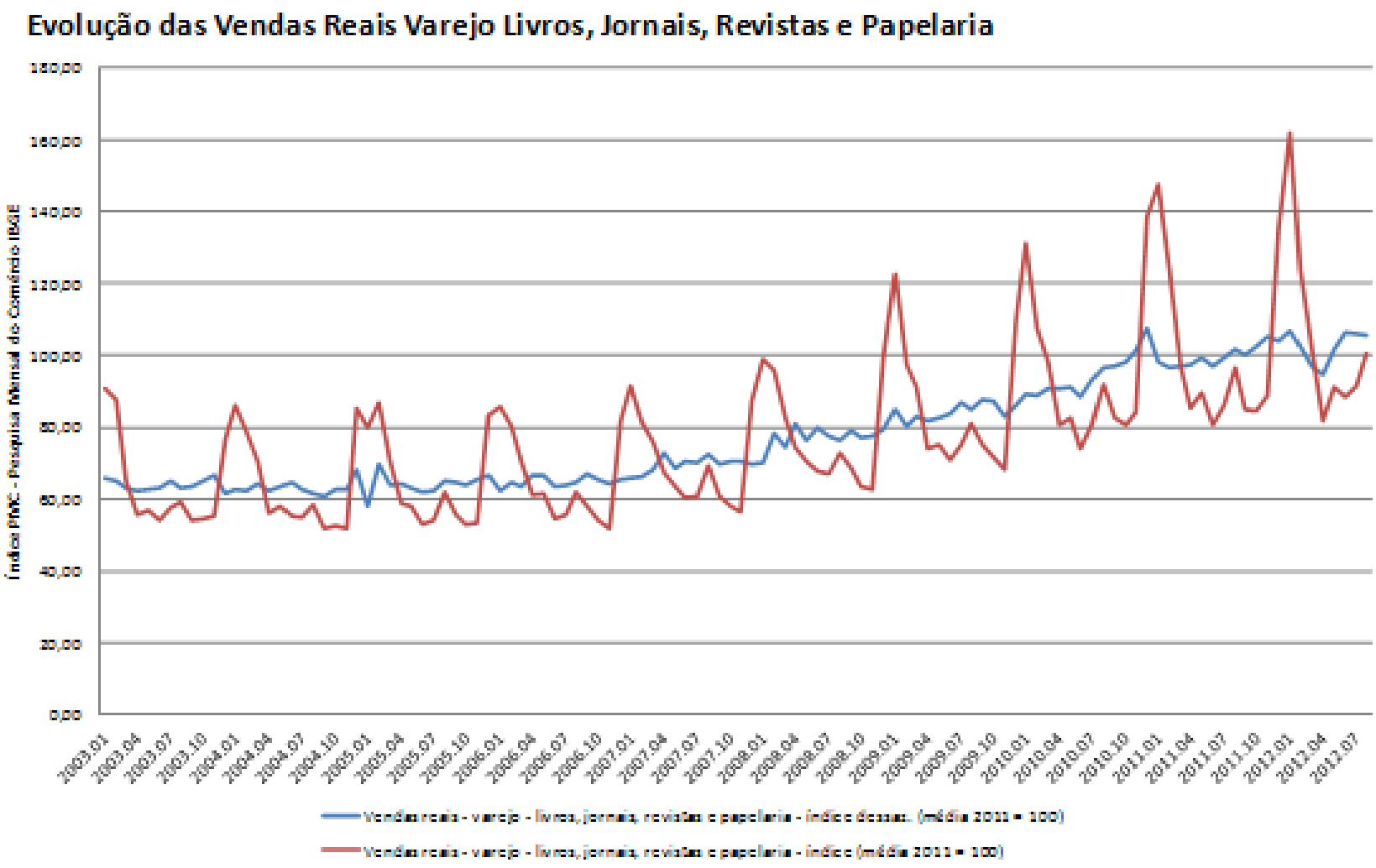

